\title{
Development and Validation of a Method for the Detection of Titanium Dioxide Particles in Human Tissue with Single Particle ICP-MS
}

\section{Ruud JB Peters ${ }^{1 *}$, Anna K Undas ${ }^{1}$, Joost Memelink', Greet van Bemmel'1, Sandra Munniks ${ }^{1}$, Hans Bouwmeester ${ }^{1}$, Peter Nobels ${ }^{2}$, Wobbe Schuurmans ${ }^{2}$ and Martijn K van der Lee ${ }^{1}$}

${ }^{1}$ Department of Contaminants and Toxins, RIKILT, Wageningen University \& Research, The Netherlands

${ }^{2}$ Department of Soil Quality, Wageningen University \& Research, The Netherlands

\begin{abstract}
Human biomonitoring studies to determine total titanium (total-Ti) and titanium dioxide $\left(\mathrm{TiO}_{2}\right)$ particles require very sensitive inductively coupled plasma high resolution mass spectrometry (ICP-HRMS) methods. The result of such studies can only be reliably when used in a risk assessment if the analytical methods are fully validated, as reported here for human liver and spleen. For total-Ti an acidic $\mathrm{HNO}_{3} / \mathrm{HF}$ digestion was applied, followed by ICP-HRMS analysis of the acidic digests. For $\mathrm{TiO}_{2}$ particles a two-step digestion procedure was developed. In the first step the formaldehyde-fixed tissue was depolymerized and in the second step an enzymatic digestion was performed. Sample digests were analyzed with ICP-HRMS operated in single particle mode to detect $\mathrm{TiO}_{2}$ particles. Both methods were validated according to NEN 7777 using a scheme of duplicate analysis over an eight day period. Detection limits for total-Ti and $\mathrm{TiO}_{2}$ particles were 0.01 and $0.005 \mathrm{mg} \mathrm{Ti} / \mathrm{kg}$ with a particle size quantification limit of $85 \mathrm{~nm}$ for $\mathrm{TiO}_{2}$ particles. Repeatability and reproducibility were $24 \%$ and $31 \%$ for the total titanium concentration, $22 \%$ and $39 \%$ for the particle titanium concentration, and $29 \%$ and $24 \%$ for the titanium dioxide particle size. In total 30 human tissue samples were analyzed with the developed and validated method. The results show a total-Ti content in the range of $0.02-0.09 \mathrm{mg} \mathrm{Ti} / \mathrm{kg}$ in liver and $0.02-0.4 \mathrm{mg} \mathrm{Ti} / \mathrm{kg}$ in spleen. The concentrations of particle $\mathrm{TiO}_{2}$ ranged from $0.01-0.08 \mathrm{mg} \mathrm{Ti} / \mathrm{kg}$ in liver and from $0.01-0.1 \mathrm{mg} \mathrm{Ti} / \mathrm{kg}$ in spleen. On the average, particle $\mathrm{TiO}_{2}$ explained up to $67 \%$ of the total- $\mathrm{Ti}$ concentrations. The detected $\mathrm{TiO}_{2}$ particles had a particle size range of 85 to $720 \mathrm{~nm}$.
\end{abstract}

Keywords

Nanoparticles, Titanium dioxide, Human tissue, Validation, Single particle ICP-MS

\section{Introduction}

Titanium dioxide $\left(\mathrm{TiO}_{2}\right)$ is industrially produced in high volumes with an estimated global annual production volume of up to 9 million metric tons [1]. $\mathrm{TiO}_{2}$ applied as titanium white is an authorized ingredient in food, consumer and medicinal products (i.e. in the EU as E171 and by the FDA as a food color additive and food contact substance in food packaging). Typical particle sizes of $\mathrm{TiO}_{2}$ pigments are in the range of 50 to $500 \mathrm{~nm}$ indicating that part of these pigments are actually nanomaterials [2,3]. No acceptable daily intake (ADI) for oral ingestion of $\mathrm{TiO}_{2}$ has been derived in the past due to the absence of observed toxic effects in the available chronic rodent study [4], the generally assumed negligible uptake of $\mathrm{TiO}_{2}$ following ingestion [5], and the assumed insolu- bility and inertness of the material [6]. However, recent human volunteer studies show elevated blood Ti levels 6 hrs. after ingestion of food grade $\mathrm{TiO}_{2}[7,8]$. Recent studies with $\mathrm{TiO}_{2}$ nanoparticles show that repeated exposure to these particles may result in significant tissue accumulation at a higher age [9-11]. In addition, it was shown

${ }^{*}$ Corresponding author: Ruud JB Peters, Department of Contaminants and Toxins, RIKILT, Wageningen University \& Research, The Netherlands, Tel: +31-317-480-671

Accepted: September 27, 2018:

Published online: September 29, 2018

Citation: Peters RJB, Undas AK, Memelink J, et al. (2018) Development and Validation of a Method for the Detection of Titanium Dioxide Particles in Human Tissue with Single Particle ICP-MS. Current Trends Anal Bioanal Chem 2(1):74-84

Copyright: (c) 2018 Peters RJB, et al. This is an open-access article distributed under the terms of the Creative Commons Attribution License, which permits unrestricted use, distribution, and reproduction in any medium, provided the original author and source are credited. 
Citation: Peters RJB, Undas AK, Memelink J, et al. (2018) Development and Validation of a Method for the Detection of Titanium Dioxide Particles in Human Tissue with Single Particle ICP-MS. Current Trends Anal Bioanal Chem 2(1):74-84

that $\mathrm{TiO}_{2}$ nanoparticles can have toxic effects $[12,13]$. Therefore, it is relevant to assess whether the exposure to $\mathrm{TiO}_{2}$ particles can lead to health risks [14]. First assessments in this direction have been performed by Bachler, et al. and Heringa, et al. who estimated the oral intake of $\mathrm{TiO}_{2}$ nanoparticles and calculated the resulting steady state organ concentrations $[15,16]$.

Yet, no measured data are available on the presence of $\mathrm{TiO}_{2}$ particles in human organs and actually no validated analytical method is available to detect low levels of $\mathrm{TiO}_{2}$ particles in biological and human matrices. For biomonitoring purposes it is useful to determine both the total titanium content (total-Ti) and the presence of $\mathrm{TiO}_{2}$ particles (particulate- $\mathrm{TiO}_{2}$ ), the latter in terms of concentration and particle size (distributions). Total-Ti content is routinely determined by using standard inductively coupled plasma high resolution mass spectrometry (ICP-HRMS), whereas for determination of particulate- $\mathrm{TiO}_{2}$ several particle specific detection methods can be considered. However, taking into account the expected low particle concentrations, single particle ICP-HRMS (spICP-HRMS) is the most logical choice. spICP-(HR)MS is an innovative method for the detection and characterization of metal and metal oxide particles in products, food, biota and environmental samples $[17,18]$. In spICP-MS the aqueous sample is introduced continuously into a standard ICP-MS system that is set to acquire data with a high time resolution. Following nebulization, a fraction of the nanoparticles enter the plasma where they are atomized and ionized resulting in a cloud of ions. This cloud of ions is sampled by the mass spectrometer and since the ion density in this cloud is high, the signal pulse is high compared to the background signal. The number of pulses detected per second is directly proportional to the number of nanoparticles in the aqueous suspension that is being measured. The intensity of the pulse is directly proportional to the mass of the measured element in a nanoparticle, and thereby to the nanoparticle's diameter to the third power (i.e. assuming a spherical geometry for the nanoparticle). Current limitations are the minimum particle diameter that can be observed and that is about $50 \mathrm{~nm}$ for $\mathrm{TiO}_{2}$ particles. Very recently, the method was also published as an ISO Technical Specification [19] and data processing software is available from some instrument suppliers and from the internet [13]. The method was validated for the determination of silver nanoparticles in chicken meat [20]. Based on our previous work we now aimed to develop a sample preparation and detection method for total- $\mathrm{Ti}$ and particulate- $\mathrm{TiO}_{2}$ in biological tissues. In this work we describe the analytical methods and highlight the critical issues in validation of a detection method for (nano)particles and describe the results of the validation.

\section{Materials and Methods}

A Milli-Q-Plus ultrapure water system from Millipore (Amsterdam, The Netherlands) was used to obtain ultrapure water (UPW) for sample preparation and dilution of standards and sample suspensions. $70 \% \mathrm{HNO}_{3}$ (J.T. Baker, Deventer, The Netherlands) and 40\% HF (Merck, Darmstadt, Germany) were of analytical quality. Proteinase K (30 U/mg, $7.5 \mathrm{mg} / \mathrm{mL}$ ) was obtained from Sigma-Aldrich (Zwijndrecht, The Netherlands). Tris (hydroxymethyl) aminomethane buffer $\left(\mathrm{H}_{2} \mathrm{NC}\left(\mathrm{CH}_{2} \mathrm{OH}\right)_{3}\right)$ was obtained from Merck (Darmstadt, Germany) and glycine was obtained from VWR Amresco (Solon, OH, USA). Sodium dodecyl sulphate (SDS) was obtained from Acros Organics (Belgium), while sodium chloride $(\mathrm{NaCl})$ and ethylene diamine tetra acetic acid (EDTA) were obtained from Sigma-Aldrich (Zwijndrecht, The Netherlands). Ethanol absolute (Merck, Darmstadt, Germany) and Bovine serum albumin (BSA) (Sigma-Aldrich, Zwijndrecht, The Netherlands) were used to disperse particle material. The digestion buffer was prepared by dissolving $12.1 \mathrm{~g}$ of Tris buffer, $0.37 \mathrm{~g}$ EDTA, $20 \mathrm{~g}$ SDS, $15 \mathrm{~g}$ glycine and $11.7 \mathrm{~g} \mathrm{NaCl}$ in $1 \mathrm{~L}$ of UPW followed by mixing with a magnetic stirrer until completely dissolved. Certified ionic titanium and rhodium standards were obtained from Inorganic Ventures (Christianburg, USA). Calibration standards in the concentration range of $0.5-10 \mu \mathrm{g} / \mathrm{L}$ (for total-Ti determination) and 125-500 $\mu \mathrm{g} / \mathrm{L}$ (for particulate $\mathrm{TiO}_{2}$ determination) were prepared on the day of analysis by diluting the stock standards in the acidic sample matrix. Reference (nano)particle material NM$104\left(\mathrm{TiO}_{2}\right)$ was obtained from the Joint Research Center of the European Commission (Ispra, Italy) and was dispersed according to the NanoGenotox protocol [21]. RM8013 is a reference material consisting of a $50 \mathrm{mg} / \mathrm{L}$ aqueous suspension of $60 \mathrm{~nm}$ spherical gold nanoparticles stabilized in a citrate buffer and was obtained from NIST (Boulder, CO, USA). Working standards for the determination of the ICP-MS transport efficiency were prepared daily by diluting RM8013 to $50 \mathrm{ng} / \mathrm{L}$ in UPW.

\section{Samples and sample preparation}

Since the methods will be used for biomonitoring purposes, we used post mortem human liver and spleen samples. The complete and intact organs were derived from 15 bodies that were donated to the Department of Anatomy of the University Medical Centre Utrecht. From these persons a written informed consent was obtained during life that allowed the use of their entire bodies for educational and research purposes. The bodies had been fixed in $4 \%$ formaldehyde. Following removal, the organs were stored at room temperature in a $4 \%$ formaldehyde solution. During sample preparation each organ was cut into small pieces using stainless steel 
Citation: Peters RJB, Undas AK, Memelink J, et al. (2018) Development and Validation of a Method for the Detection of Titanium Dioxide Particles in Human Tissue with Single Particle ICP-MS. Current Trends Anal Bioanal Chem 2(1):74-84

knifes and the pieces were grinded to a size range of 0.5 $1 \mathrm{~mm}$ diameter. Each grinded sample was homogenized and 10 subsamples of 10 gram each were collected. The subsamples were stored in the freezer at $-80^{\circ} \mathrm{C}$. To determine potential sample contamination all materials that have been in contact with the organs were collected. This included the formaldehyde used to fix the body tissues, scalpels used to remove the organs, and knifes and utensils used during sample processing and homogenization. The total-Ti concentration in these materials ( $4 \%$ formaldehyde solution) or released by these materials was determined. For the latter the materials were sonicated for $15 \mathrm{~min}$ in UPW and the water analyzed. The sum of the blank additions was lower than the limit of detection (LOD) of the chemical analysis method for the tissues.

\section{Determination of total-Ti content}

An analytical sample of $1 \mathrm{~g}$ was collected from each grinded and homogenized sample and brought into a perfluoroalkoxy (PFA) microwave digestion tube to which $6 \mathrm{~mL}$ of nitric acid $\left(70 \% \mathrm{HNO}_{3}\right)$ and $2 \mathrm{~mL}$ of hydrofluoric acid (40\% HF), were added. All subsamples were digested for $55 \mathrm{~min}$ in a MARS microwave system (CEM Corporation, Matthews, NC, USA). The temperature program was as follows: at $1600 \mathrm{~W}$ power from 20 to $120^{\circ} \mathrm{C}$ in $15 \mathrm{~min}$, then to $160^{\circ} \mathrm{C}$ in $10 \mathrm{~min}$, and then to $210^{\circ} \mathrm{C}$ in $30 \mathrm{~min}$ and hold for $1 \mathrm{~min}$. Following digestion and cooling to room temperature, UPW was added to a total volume of $50 \mathrm{~mL}$. The extracts were shaken manually, diluted 2 times, and analyzed with ICP-HRMS as described in the next section. Quantification was based on ionic titanium standards diluted in the same acidic matrix as the samples. Method blanks were determined by performing the complete procedure, however, without the addition of a sample. The total-Ti content in the blanks was below the method LOD.

\section{Determination of $\mathrm{TiO}_{2}$ particles}

For the determination of particle- $\mathrm{TiO}_{2}$ a digestion procedure is followed to liberate the particles. This digestion procedure consists of two steps. In the first step the tissue in the formaldehyde-fixed sample is depolymerized, while in the second step a standard enzymatic digestion is performed. An analytical sample of $200 \mathrm{mg}$ was collected from the grinded subsamples and brought into a $12-\mathrm{mL}$ PE tube. In the first step, $4 \mathrm{~mL}$ of the digestion buffer (containing glycine) was added and the sample was vigorously vortexed for $30 \mathrm{sec}$. The tube was heated for $3 \mathrm{hrs}$. at $100^{\circ} \mathrm{C}$ to depolymerize the formaldehyde-fixed tissue. In the second step, and after cooling to room temperature, $910 \mu \mathrm{L}$ of proteinase $\mathrm{K}(2.5 \mathrm{mg} / \mathrm{ml})$ was added. The tube was incubated for $16 \mathrm{hrs}$. at $37^{\circ} \mathrm{C}$ in a shaking water bath. After cooling to room temperature, the digest was diluted with UPW and analyzed using
spICP-HRMS. Just prior to the instrumental analysis, the sample digest was homogenized by 1 minute sonication to prevent particle agglomeration and sedimentation.

\section{Instrumental analysis with ICP-HRMS}

A Thermo Finnigan Element 2 (Thermo Fisher Scientific $\mathrm{GmbH}$, Bremen, Germany), a sector-field based high resolution ICP-MS, was used to measure total-Ti in acidic extracts in standard mode and $\mathrm{TiO}_{2}$ particles in single-particle mode (also called time resolved analysis mode). The Thermo Finnigan Element 2 was operated at a forward power of $1300 \mathrm{~W}$ and the argon gas flows were at the following settings; plasma, $15.4 \mathrm{~L} / \mathrm{min}$; nebulizer around $1 \mathrm{~L} / \mathrm{min}$ and optimized daily; auxiliary, $1.2 \mathrm{~L} /$ $\mathrm{min}$. The sample flow rate to the nebulizer was set at 0.5 $\mathrm{mL} / \mathrm{min}$. Data acquisition was done in standard mode and in time resolved analysis mode with titanium measured at $\mathrm{m} / z 46.95$ in medium resolution mode. Interferences on $m / z 46.95$, e.g. ${ }^{31} \mathrm{P}^{16} \mathrm{O},{ }^{14} \mathrm{~N}^{16} \mathrm{O}_{2}{ }^{1} \mathrm{H}$ and ${ }^{15} \mathrm{~N}^{16} \mathrm{O}_{2}$, are easily separated from $\mathrm{Ti}$ in medium resolution mode. A peculiarity of the Thermo Element 2 is that in medium resolution mode the instrument measures not one mass but a range of slightly differing masses closely around the monitored isotope, and that two different masses (typically $0.01 \mathrm{amu}$ apart) have to be monitored as a minimum. Measuring a single mass as with quadrupole instruments is not possible. In this study 3 masses were measured, the monitored isotope (at $\mathrm{m} / z$ 46.95) and one mass left and one mass right from the monitored isotope. In standard and time resolved mode the dwell time was 250 and 2 ms respectively, with a total acquisition time of $60 \mathrm{~s}$. In spICP-HRMS a $2 \mathrm{~ms}$ dwell time was chosen since this provides an accurate result in terms of particle counting [13]. The transport efficiency was determined by the analyses of a $50 \mathrm{ng} / \mathrm{L}$ diluted aqueous RM8013 (60 nm gold nanoparticle) suspension under the same instrumental conditions as the samples but monitoring $m / z 197$ for gold. Finally, single-particle data were exported as a csv file and processed in a dedicated spreadsheet for the calculation of particle sizes, particle size distributions, and particle number and mass concentrations. Details about this spreadsheet and the calculation of the parameters can be found elsewhere [13]. Method blanks were determined by performing the complete procedure, however, without the addition of a sample. The mass-based $\mathrm{TiO}_{2}$ particle concentrations in the blanks were below the method LOD. Since the blanks of the sampling materials were below the LOD of the total-Ti method they were not involved in the particle analysis.

\section{Validation procedure}

The complete procedure for total- $\mathrm{Ti}$ and particle- $-\mathrm{TiO}_{2}$ was validated to determine the performance characteris- 
Citation: Peters RJB, Undas AK, Memelink J, et al. (2018) Development and Validation of a Method for the Detection of Titanium Dioxide Particles in Human Tissue with Single Particle ICP-MS. Current Trends Anal Bioanal Chem 2(1):74-84

Table 1: Validation scheme for an 8 days validation of the total-Ti and particle- $\mathrm{TiO}_{2}$ determination in human tissue (liver and spleen) based on duplicate analysis.

\begin{tabular}{|c|c|c|c|c|c|c|c|c|c|}
\hline Laboratory Sample & Performance Characteristic & Day 1 & Day 2 & Day 3 & Day 4 & Day 5 & Day 6 & Day 7 & Day 8 \\
\hline Sample 1 (liver) & repeatability/reproducibility & $x x$ & & & & $x$ & & & \\
\hline Sample 2 (spleen) & repeatability/reproducibility & $x$ & & & & $x x$ & & & \\
\hline Sample 3 (liver) & repeatability/reproducibility & & $x x$ & & & & $x$ & & \\
\hline Sample 4 (spleen) & repeatability/reproducibility & & $x$ & & & & $x x$ & & \\
\hline Sample 5 (liver) & repeatability/reproducibility & & & $x x$ & & & & $\mathrm{x}$ & \\
\hline Sample 6 (spleen) & repeatability/reproducibility & & & $x$ & & & & $x x$ & \\
\hline Sample 7 (liver) & repeatability/reproducibility & & & & $x x$ & & & & $x$ \\
\hline Sample 8 (spleen) & repeatability/reproducibility & & & & $x$ & & & & $x x$ \\
\hline Laboratory sample lose to detection limit & detection limit & $x$ & $x$ & $\mathrm{x}$ & $x$ & $x$ & $\mathrm{x}$ & $x$ & $x$ \\
\hline Matrix matched & trueness & $x$ & $x$ & $x$ & $x$ & $x$ & $x$ & $x$ & $x$ \\
\hline Sample blanks & selectivity & $\mathrm{x}$ & $x$ & $\mathrm{x}$ & $x$ & $x$ & $\mathrm{x}$ & $\mathrm{x}$ & $\mathrm{x}$ \\
\hline Sample under deiviating circumstances & robustness & $x x$ & & & & & & & \\
\hline
\end{tabular}

$\mathrm{X}$ : Single measurement; $\mathrm{xx}$ : Double measurement under repeatable conditions.

tics of the methods. The validation was carried out for the measurands mass concentration in the total-Ti determination, and for the particle size, particle number- and particle mass-based concentration in the particle- $\mathrm{TiO}_{2}$ determination. For the parameter particle size it should be noted that the NM-104 material has not one uniform particle size but a size distribution in the range of 50-200 $\mathrm{nm}$. Therefore, the apex of the size distribution was used as particle size parameter. The validation was performed according to NEN 7777, "Environment and Food - Performance characteristics of measurement methods"[22], as presented in Table 1. The validation protocol is based on the analysis and comparison of duplicate samples on the same and different days.

Linearity: In the spICP-HRMS method particle size is calculated from a calibration line of ionic Ti, similar to what is used in the total-Ti determination. Therefore linearity is determined for the range of $0.5-10 \mu \mathrm{g} / \mathrm{L}$ for total- $\mathrm{Ti}$ and for the range of $25-500 \mu \mathrm{g} / \mathrm{L}$ for particle- $\mathrm{TiO}_{2}$.

LOD and LOQ: Following the NEN7777, the limit of detection (LOD) for the total-Ti determination is calculated as 3 times the standard deviation in the results of a sample with a total-Ti content close to the expected LOD. This sample is analysed on each of the validation days. In accordance, the limit of quantification (LOQ) is calculated as 10 times this standard deviation. The LOD and LOQ are calculated as follows:

$L O D=3 \times \sqrt{\frac{\sum_{i=1}^{k}\left(y_{i}-m\right)^{2}}{k-1}}$ and $L O Q=10 \times \sqrt{\frac{\sum_{i=1}^{k}\left(y_{i}-m\right)^{2}}{k-1}}$

where, $k$ is the number of samples, $y_{i}$ is the result of a single sample and $\mathrm{m}$ is average result of the single samples.

For particle- $\mathrm{TiO}_{2}$ determined with spICP-HRMS the situation is different and the main challenge in the processing of the spICP-HRMS data is the discrimination between the background (chemical noise and dissolved signals) and true particulate signals. In this study an iterative approach as described in the literature is used to determine the mean background intensity, $\mu_{\mathrm{bg}}$, and the standard deviation, $\sigma_{\mathrm{bg}}$, of the background and/or dissolved Ti signal from the raw data [23,24]. To separate particle events from the background a particle detection threshold of $7 \sigma_{\mathrm{bg}}$ was used. Only peaks with an intensity higher than $\mu_{\mathrm{bg}}+7 \sigma_{\mathrm{bg}}$, were considered as particle events. This comparatively high threshold of $7 \sigma_{\mathrm{bg}}$ was chosen to minimize the contribution of dissolved signal to the particle counts.

For particle- $\mathrm{TiO}_{2}$ there are two LOD values, one for the number- and mass-based concentration $\left(\mathrm{LOD}_{\mathrm{C}}\right)$, and one for particle size $\left(\mathrm{LOD}_{\mathrm{S}}\right)$. $\mathrm{LOD}$ equals the minimum number of particle peaks in the time scan that differentiates a sample from a blank. This is another challenge in spICP-MS data processing since false positive signals may be present from electronic spikes and carry-over of particles adsorbed in the analytical system. A way to determine $\mathrm{LOD}_{C}$ is by the IUPAC recommended approximation (Poisson) described as [25],

$$
L O D_{C}=3.29 \times \sqrt{N}+2.72
$$

where $\mathrm{N}$ is the number of particle peaks observed in the time scan of a blank. Even if no peaks are observed in the time scan there will be a minimum $\mathrm{LOD}_{\mathrm{C}}$. The particle number $\mathrm{LOD}_{\mathrm{C}}$ can be converted into mass units if the size and density of the particle are known. The determination of the $\mathrm{LOD}_{\mathrm{S}}$ is described by Lee, et al. and can be estimated as follows (except that Lee's $3 \sigma_{\mathrm{bg}}$ here is replaced by $7 \sigma_{\mathrm{bg}}$ ) [26],

$$
L O D_{S}=\sqrt[3]{\frac{6 \times 7 \sigma_{b g}}{R \times f_{a} \times \rho \times \pi}}
$$

where $\sigma_{\mathrm{bg}}$ is the standard deviation in the background noise in the time scan, $\mathrm{R}$ is the ICP-MS response (cps/ $\mu \mathrm{g}), \mathrm{f}_{\mathrm{a}}$ is the mass fraction of analysed element in the 
Citation: Peters RJB, Undas AK, Memelink J, et al. (2018) Development and Validation of a Method for the Detection of Titanium Dioxide Particles in Human Tissue with Single Particle ICP-MS. Current Trends Anal Bioanal Chem 2(1):74-84

nanoparticle and $\varrho$ is the density of the nanoparticle material $\left(\mathrm{g} / \mathrm{cm}^{3}\right)$. To be representative the $\sigma_{\mathrm{bg}}$ should be determined in the time scan of a real sample, not in a blank.

Repeatability and within-lab reproducibility: Repeatability and within-lab reproducibility are determined by the analysis of 3 samples on each of the validation days (see Scheme 1 ). The repeatability $\left(\mathrm{s}_{\mathrm{r}}\right)$ and within-lab reproducibility $\left(\mathrm{s}_{\mathrm{RL}}\right)$ standard deviation are calculated as follows:

$$
S_{r}=\sqrt{\frac{\sum_{i=1}^{k} d_{i}^{2}}{2 k}} \quad S_{R L}=\sqrt{\frac{\sum_{i=1}^{k}\left(y_{i}-m_{i}\right)^{2}}{2 k}}
$$

where $\mathrm{k}$ is the number of samples, di is the difference between samples analysed on the same day, $m_{i}=$ the average value of samples analysed on the same day, and $\mathrm{y}_{\mathrm{i}}=$ the value of the single sample analysed on the following day.

Trueness: Since no reference materials are available, matrix matched standards spiked with NM-104 at 2 and $4 \mathrm{mg} \mathrm{Ti} / \mathrm{kg}$ tissue were analysed for the determination of trueness. The trueness is calculated as follows:

$$
\operatorname{Trueness}(\%)=\frac{\left(C_{3}-C_{1}\right)}{C_{2}} * 100
$$

where, $\mathrm{C}_{1}$ is the concentration in the blank sample, $\mathrm{C}_{2}$ the spike concentration, and $\mathrm{C}_{3}$ the concentration in the spiked sample.

Selectivity: The selectivity of the total-Ti and particle- $\mathrm{TiO}_{2}$ methods is not separately tested but based on possible (poly)atomic interferences. For the most abundant Ti isotope, $m / z 48$, isobaric interferences arise from e.g. ${ }^{36} \mathrm{Ar}^{12} \mathrm{C},{ }^{32} \mathrm{~S}^{16} \mathrm{O}$ and ${ }^{48} \mathrm{Ca}$, and therefore Ti was measured in medium resolution mode at $\mathrm{m} / z$ 46.95. In addition, the selectivity of the method is determined by analysing blank samples (chemical blank, no matrix) on each validation day.

Robustness: Robustness was determined for total-Ti only. Samples were digested with $2 \mathrm{~mL} \mathrm{HNO}_{3}$ and $6 \mathrm{~mL}$ $\mathrm{HF}$, instead of the correct digestion by $6 \mathrm{~mL} \mathrm{HNO}_{3}$ and 2 mL HF.

Stability: The stability of the digests was determined by re-analysis of acidic and enzymatic sample digests prepared on day 3 of the validation. For total-Ti, the digests were reanalysed after 4 and 12 days, for particle- $\mathrm{TiO}_{2}$ this was after 2 days.

\section{Results}

\section{Method validation}

The analytical method was validated for the measurands mass concentration in the total-Ti determination, and particle size, particle number- and particle mass-based concentration in the particle- $\mathrm{TiO}_{2}$ determination.
The results of this validation are presented in this section.

Linearity: The linearity of the total-Ti and the particle- $\mathrm{TiO}_{2}$ method was determined from the ionic calibration standards that were analysed on each validation day. In the case of total-Ti determination, rhodium was used as an internal standard. The calibration lines of each of the eight validation days were similar, indicating only small differences in day-to-day ICP-MS response despite the fact that in between validation days the instrument was used for other analysis and was shut down. In all cases the correlation coefficient was $>0.99$.

LOD and LOQ: For total-Ti the LOD and LOQ were estimated from the signal in a sample with a low total-Ti content and were found to be 0.01 and $0.03 \mathrm{mg} \mathrm{Ti} / \mathrm{kg}$, respectively. The lower limit of particle size detection was visually estimated as $85 \mathrm{~nm}$ from the time scans of actual samples. The $\mathrm{LOD}_{\mathrm{S}}$ was also calculated from the standard deviation of the background signal and the sensitivity of the analysis as described by Lee, et al. [21], however after replacing $3 \sigma_{\mathrm{bg}}$ by $7 \sigma_{\mathrm{bg}}$ to be extra conservative in the definition of particles. The $\mathrm{LOD}_{\mathrm{S}}$ for $\mathrm{TiO}_{2}$ particles in the spICP-HRMS analysis was calculated to be $50 \mathrm{~nm}$. Based on the linearity of the ionic concentration range that is used for sizing the $\mathrm{TiO}_{2}$ particles, the upper working range for size is at least $500 \mathrm{~nm}$. Thus, the working range for the detection of $\mathrm{TiO}_{2}$ particles in tissues ranges from 50 to $500 \mathrm{~nm}$. The $\mathrm{LOQ}_{\mathrm{S}}$ (size) was estimated from the $\mathrm{LOD}_{\mathrm{s}}$ and the (within-lab) reproducibility of the size determination as follows,

$$
L O Q_{S}=L O D_{S}+3 \times \sigma_{\text {size }}=50+3 \times 12=86 \mathrm{~nm}
$$

where $\sigma_{\text {size }}$ is the within-lab reproducibility for particle size. This $L O Q_{S}$ is in agreement with visual estimation of the lower limit of the working range for particle size.

The particle mass concentration limit, $\mathrm{LOD}_{\mathrm{C}}$, is based on the average number of peaks observed in the blank matrix samples. In total 8 blank matrix samples were analysed (one each validation day) and the number of observed peaks in these samples ranged from 4 to 37 with an average of $20 \pm 8$. Based on the average plus $3 \sigma$, the particle number based $\mathrm{LOD}_{C}$ is 44 particle peaks. The particle mass $\mathrm{LOD}_{C}$ based on an average $\mathrm{TiO}_{2}$ particle size of $100 \mathrm{~nm}$ is $88 \mathrm{fg}$. With an ICP-MS influx of 0.5 $\mathrm{mL} / \mathrm{min}$ this is $176 \mathrm{fg} / \mathrm{mL}$ in the final extract and taking into account the sample preparation, the $\mathrm{LOD}_{\mathrm{C}}$ in tissue is $0.005 \mathrm{mg} \mathrm{TiO} / 2 \mathrm{~kg}$. At the upper end of the working range, the maximum number of peaks observed in the time scan should be limited to $10 \%$ of the total number of dwell time intervals to avoid multiple particles events. The number of dwell time intervals in the time scan is $10,000 / \mathrm{min}$ and therefore the maximum number of peaks in the 1 min time scan should not exceed 1000. If samples showed more peaks than this, the sample was 
Citation: Peters RJB, Undas AK, Memelink J, et al. (2018) Development and Validation of a Method for the Detection of Titanium Dioxide Particles in Human Tissue with Single Particle ICP-MS. Current Trends Anal Bioanal Chem 2(1):74-84

diluted and re-analysed. With a maximum of 1000 particle peaks, the upper limit of the working range for $\mathrm{TiO}_{2}$ particles is $0.3 \mathrm{mg} \mathrm{TiO} / \mathrm{kg}$. Thus, the working range for $\mathrm{TiO}_{2}$ particles ranges from 0.005 to $0.3 \mathrm{mg} \mathrm{TiO} / 2 \mathrm{~kg}$. The $\mathrm{LOQ}_{\mathrm{C}}$ is based on the average number of peaks in the blank plus 10 , i.e. 100 particle peaks. Based on a $100 \mathrm{~nm}$ $\mathrm{TiO}_{2}$ particle the $\mathrm{LOQ}_{\mathrm{C}}$ is $0.01 \mathrm{mg} \mathrm{TiO} / 2 / \mathrm{kg}$ tissue.

The false positive signals that were encountered in the blank matrix samples will also be present in true samples and may significantly increase the total particle count for samples of low particle number concentrations. In order to reliably report detected particle numbers, we define a confidence threshold for detected particle numbers represented by the average number of false positives detected in the blank matrix samples plus $10 \sigma$, i.e. the $\mathrm{LOQ}_{C}$, and this value was subtracted from the particles detected in each sample.

Specificity and selectivity: $\mathrm{Ti}$ was measured at $\mathrm{m} / \mathrm{z}$ 46.95 in medium resolution mode. $\mathrm{m} / z 47.95$ was not used because of the interference of ${ }^{48} \mathrm{Ca}$ that could only just be separated from $\mathrm{Ti}$ in high resolution mode. The interferences on $m / z$ 46.95, e.g. ${ }^{31} \mathrm{P}^{16} \mathrm{O},{ }^{14} \mathrm{~N}^{16} \mathrm{O}{ }_{2}{ }^{1} \mathrm{H}$ and ${ }^{15} \mathrm{~N}^{16} \mathrm{O}_{2}$ are easily being separated from $\mathrm{Ti}$ in medium resolution mode. Even at medium resolution doubly charged ion interference from ${ }^{94} \mathrm{Mo}^{++}$and ${ }^{94} \mathrm{Zr}^{++}$is possible. However, ${ }^{94} \mathrm{Mo}^{++}$will be reduced in the argon plasma since its second ionization potential is higher than the first ionization potential of Ar. For ${ }_{94} \mathrm{Zr}^{++}$the second ionization potential is less than the first ionization potential of $\mathrm{Ar}$ and therefore it can be formed in the plasma. In practice no interferences were found in the analysis of chemical blank samples and therefore it was concluded that the method is specific. Selectivity was determined by the analysis of 8 chemical blank matrix samples. In all cases the number of peaks that were observed in the time scan are below the $\mathrm{LOD}_{\mathrm{C}}$ and therefore the method is selective.

Repeatability and within-lab reproducibility: The repeatability $(\mathrm{sr})$ and within-lab reproducibility $\left(\mathrm{S}_{\mathrm{RL}}\right)$ were determined by analysing 3 samples on each of the 8 validation days as described in Table 1 . The measurement data were evaluated for total-Ti concentration, particle diameter, particle number- and particle mass-based concentration. The results for repeatability and within-lab reproducibility are presented in Table 2 . To determine

Table 2: Validation results for repeatability and within-lab reproducibility for total- $\mathrm{Ti}$ and particle- $\mathrm{TiO}_{2}$ in human tissue. Repeatability and intermediate precision are expressed as relative standard deviations.

\begin{tabular}{|l|l|l|l|}
\hline Parameter & $\begin{array}{l}\text { Concentration } \\
\text { level }\end{array}$ & $\mathbf{S}_{\mathbf{r}}(\mathbf{\%})$ & $\mathbf{S}_{\mathrm{RL}} \mathbf{( \% )}$ \\
\hline Total-Ti & as in sample & 24 & 31 \\
\hline Particle diameter & as in sample & 29 & 24 \\
\hline Particle number concentration & as in sample & 20 & 46 \\
\hline Particle mass concentration & as in sample & 22 & 39 \\
\hline
\end{tabular}

if these results are satisfactory the Horwitz ratio (HorRat) was used. The HorRat is a normalized performance parameter indicating the acceptability of methods of analysis with respect to repeatability and reproducibility [22]. It is the ratio of the observed relative standard deviation calculated from the actual performance data, to the corresponding predicted relative standard deviation calculated from the Horwitz equation $2 \mathrm{C}^{(-0.15)}$, where $\mathrm{C}$ is the concentration expressed as a mass fraction. The total- $\mathrm{Ti}$ and particle- $\mathrm{TiO}_{2}$ concentrations in the sample are in the order of $0.01 \mathrm{mg} \mathrm{Ti} / \mathrm{kg}$. The predicted Horwitz values at these concentrations are $24 \%$ for repeatability and $48 \%$ for reproducibility [27]. Since the values found for repeatability and reproducibility of the parameters are comparable to the predicted Horwitz values (i.e. within a factor of 2) they are satisfactory.

Trueness: Matrix matched standards were prepared by spiking samples with a known amount of $\mathrm{TiO}_{2}$ particles (NM-104, spiking level 2.0 and $4.0 \mathrm{mg} \mathrm{Ti} / \mathrm{kg}$ ) and analysing these samples on each of the validation days for total-Ti and particle- $\mathrm{TiO}_{2}$. For total-Ti the trueness was found to be $112 \pm 34 \%$, which is in the range of 70 to $120 \%$ and is therefore satisfactory. The trueness for particle- $\mathrm{TiO}_{2}$ can only be determined for the particle mass concentration since the $\mathrm{TiO}_{2}$ particle size is not an exact value. For the particle mass concentration of particle- $\mathrm{TiO}_{2}$ a trueness of $32 \pm 7 \%$ was found. Careful inspection showed that this low value for trueness was a result of the instability of the NM-104 spiking standard suspension used to prepare the matrix matched standards. In addition, NM-104 consists of $\mathrm{TiO}_{2}$ particles with a size range of 50-200 nm and with an $\mathrm{LOQ}_{\mathrm{s}}$ of 86 $\mathrm{nm}$, a part of this material will not be quantified. If the trueness would be corrected for these effects, the average trueness would be found to be $63 \pm 8 \%$. The instability of the NM-104 spiking standard suspension is probably caused by the fact that $\mathrm{TiO}_{2}$ particles are easily adsorbed and agglomerate resulting in sedimentation and a loss of $\mathrm{TiO}_{2}$ particles. Since this may also be the case in the sample digests, the trueness value of $32 \pm 7 \%$ is accepted as a worst case value. None of the results, however, were corrected for this trueness.

Robustness: The robustness of the total-Ti method was tested by changing the ratio of the acids in the acid digestion and determine their effect on the analytical result. The deviation of the results was less than 2 times $\mathrm{S}_{\mathrm{RL}}$ and therefore the total-Ti method is considered to be robust for changes in the $\mathrm{HNO}_{3} / \mathrm{HF}$ ratio in sample digestion.

Stability: Since low concentrations of ions and aqueous suspensions are inherently not stable because of adsorption effects, the stability was tested. Since it was expected that the acidic digests for total-Ti would be more 
Citation: Peters RJB, Undas AK, Memelink J, et al. (2018) Development and Validation of a Method for the Detection of Titanium Dioxide Particles in Human Tissue with Single Particle ICP-MS. Current Trends Anal Bioanal Chem 2(1):74-84

stable, the digests of these samples were re-analysed after 4 and 12 days. The results for total-Ti was within 2 times $\mathrm{S}_{\mathrm{RL}}$ indicating a good stability. The enzymatic digests of the particle- $\mathrm{TiO}_{2}$ determination were expected to be less stable due to the adsorption, agglomeration and sedimentation of $\mathrm{TiO}_{2}$ particles. These digests were therefore re-analysed after 2 days. The results indicate that particle size and the -number and mass concentrations were within 2 times $S_{R L}$ indicating a good stability. The results show that the acidic and enzymatic digests are stable for at least a period of 12 and 2 days, respectively.

Measurement uncertainty: The relative measurement uncertainty $u_{x}$ is estimated by combining the uncertainty sources, repeatability $\left(\mathrm{u}_{\mathrm{r}}\right)$, within-lab reproducibility $\left(\mathrm{u}_{\mathrm{day}}\right)$ and trueness $\left(\mathrm{u}_{\mathrm{t}}\right)$, and by using the root sum of squares approach. For the total-Ti determination, ur is $0.21, u_{\text {day }}$ is 0.33 and $u_{t}$ is 0.12 , resulting in a measurement uncertainty $u_{\mathrm{x}}$ of $41 \%$. For the measurement uncertainty of the particle size only the repeatability $\left(\mathrm{u}_{\mathrm{r}}\right)$ and within-lab reproducibility $\left(\mathrm{u}_{\mathrm{day}}\right)$ are considered, resulting in a value of $38 \%$. For the calculation of the measurement uncertainty for particle- $\mathrm{TiO}_{2}$ the more likely average trueness of $63 \pm 8 \%$ is used. In that case the measurement uncertainty of the particle number concentration is $60 \%$ and that of the particle mass-based concentration is $52 \%$. While the two latter measurement uncertainties may look high, one must take into account the low particle concentrations that were measured. An inter-laboratory comparison for the analysis of nanomaterials in water and chicken meat showed reproducibility standard deviations up to $79 \%$, highlighting the problems in any new field of analysis $[28,29]$.

\section{Total-Ti content in human liver and spleen}

To test the applicability of the developed and validated methods, 15 samples of human liver and spleen were analysed. Titanium was detected in 7 of the 15 liver samples and in 14 of the 15 spleen samples. The total-Ti content in these livers ranged from 0.02 to $0.09 \mathrm{mg} \mathrm{Ti} /$ $\mathrm{kg}$ tissue with an average value $( \pm \mathrm{SD})$ of $0.04 \pm 0.02 \mathrm{mg}$ $\mathrm{Ti} / \mathrm{kg}$ tissue. For spleen the total-Ti content ranged from 0.02 to $0.4 \mathrm{mg} \mathrm{Ti} / \mathrm{kg}$ tissue with an average value of 0.08 $\pm 0.1 \mathrm{mg} \mathrm{Ti} / \mathrm{kg}$ tissue. On the average, the total-Ti concentrations in spleen were twice or more of that in liver.
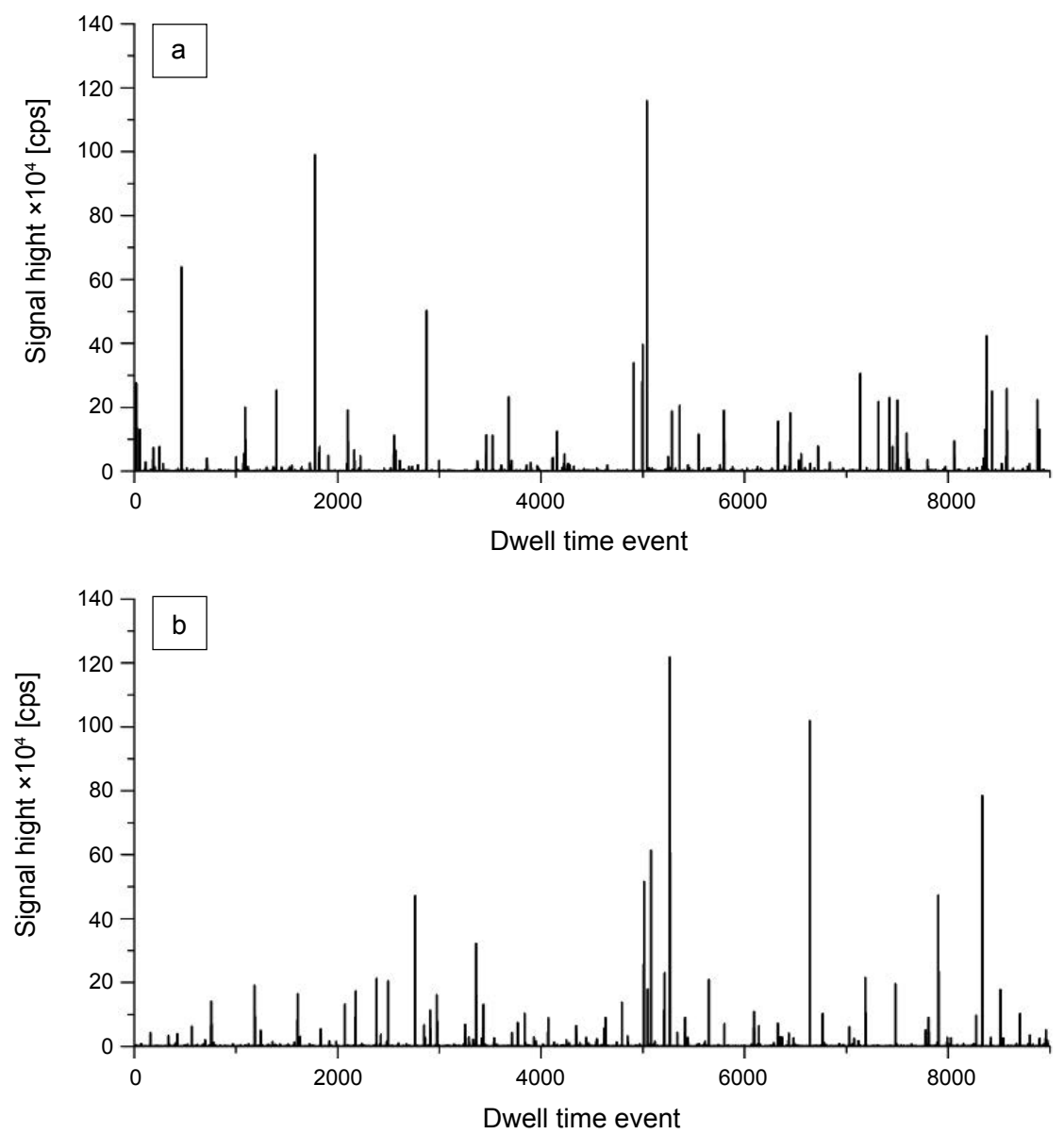

Figure 1: $\mathrm{TiO}_{2}$ particles in human (post mortem) liver and spleen. Time scans of the spICP-MS analyses of a liver (a) and spleen (b) sample for $\mathrm{TiO}_{2}$ particles. Each peak corresponds to one particle and by counting the number of peaks the particle concentrations are determined. The height of the peak corresponds with the mass of the particle from which the particle size is calculated. From the results $\mathrm{TiO}_{2}$ particles showed a size distribution from 85 to $720 \mathrm{~nm}$. 
Citation: Peters RJB, Undas AK, Memelink J, et al. (2018) Development and Validation of a Method for the Detection of Titanium Dioxide Particles in Human Tissue with Single Particle ICP-MS. Current Trends Anal Bioanal Chem 2(1):74-84

Special care was taken to include blank samples of all materials involved in organ collection, tissue processing and analyses. This includes the formaldehyde used to fix the body tissues, scalpels and knifes, and materials and utensils to process and homogenize the organs. The sum of the contributions of these materials to the total-Ti content was lower than the total-Ti LOD of the analytical method used for the tissues.

\section{Particulate- $\mathrm{TiO}_{2}$ in human liver and spleen}

A combination of gentle chemical and enzymatic digestion combined with single-particle ICP-HRMS was used for the detection and characterization of $\mathrm{TiO}_{2}$ particles. This sample preparation is known not to affect the presence and size of particles [15]. We found that most liver and spleen samples contained $\mathrm{TiO}_{2}$ particles. This is evident from the characteristic spikes in the time scans of the spICP-MS analysis of liver and spleen samples (Figure 1a and Figure 1b). In spICP-MS nanoparticles in the sample that enters the plasma are atomized and ionized producing a cloud of ions that results in a signal pulse in the mass spectrometer. These pulses are visible in the time scans in Figure 1a and Figure 1b. The number of spikes that appear during the measurement in the time scan is directly proportional to the number of particles in the sample. By counting the number of spikes in a time interval the particle concentration is calculated. The signal height of the peaks relates to the mass of the particle from which the particle size is calculated. The detected particles can consist of primary particles, aggregates or agglomerates. Particulate $\mathrm{TiO}_{2}$ was detected in 7 of the 15 liver samples and in 13 of the 15 spleen samples.

The $\mathrm{TiO}_{2}$ particle mass concentration in liver ranged from 0.01 to $0.08 \mathrm{mg} \mathrm{Ti} / \mathrm{kg}$ tissue with an average of 0.03 $\pm 0.02 \mathrm{mg} \mathrm{Ti} / \mathrm{kg}$ tissue. In spleen this concentration ran- ged from 0.01 to $0.1 \mathrm{mg} \mathrm{Ti} / \mathrm{kg}$ tissue with an average of $0.04 \pm 0.03 \mathrm{mg} \mathrm{Ti} / \mathrm{kg}$ tissue. While particle concentrations in liver and spleen in general were comparable between individuals, the concentrations in the spleen show a higher variability among different samples (as was observed for total-Ti). Tissues with high total-Ti concentrations also contained high $\mathrm{TiO}_{2}$ particle concentrations and the particulate $\mathrm{TiO}_{2}$ concentrations explained up to $67 \%$ of the total-Ti concentrations. From the spICP-MS data the particle size, particle size distribution and particle concentrations were calculated [13]. The number-based $\mathrm{TiO}_{2}$ particle size distributions in liver and spleen are comparable and have a size range of 85 to $720 \mathrm{~nm}$ with an apex of $130 \mathrm{~nm} .24 \%$ of the $\mathrm{TiO}_{2}$ particles in the number-based size distribution are $<100 \mathrm{~nm}$, i.e. nanosized according to the EU definition [30].

Small tissue grains of liver and spleen were analyzed using SEM-EDX to visualize the $\mathrm{TiO}_{2}$ particles. The electron microscope image in Figure $2 \mathrm{a}$ shows a $\mathrm{TiO}_{2}$ agglomerate below the surface of the tissue. The backscattered electron image in Figure $2 b$ reveals the spherically shaped primary particles within the agglomerate, consisting of smaller primary particles of 75-150 nm. EDX analyses showed that these particles consisted of $\mathrm{Ti}$ and $\mathrm{O}$, i.e. $\mathrm{TiO}_{2}$.

\section{Discussion}

Here we uniquely present sample preparation and a fully validated quantitative method for the analysis of low concentrations of total- $\mathrm{Ti}$ and $\mathrm{TiO}_{2}$ particles in biological samples. Validation was performed according to the highest regulatory standards as discussed in previous sections. With this method it is possible to perform reliable measurement for regulatory and law enforcement related questions.

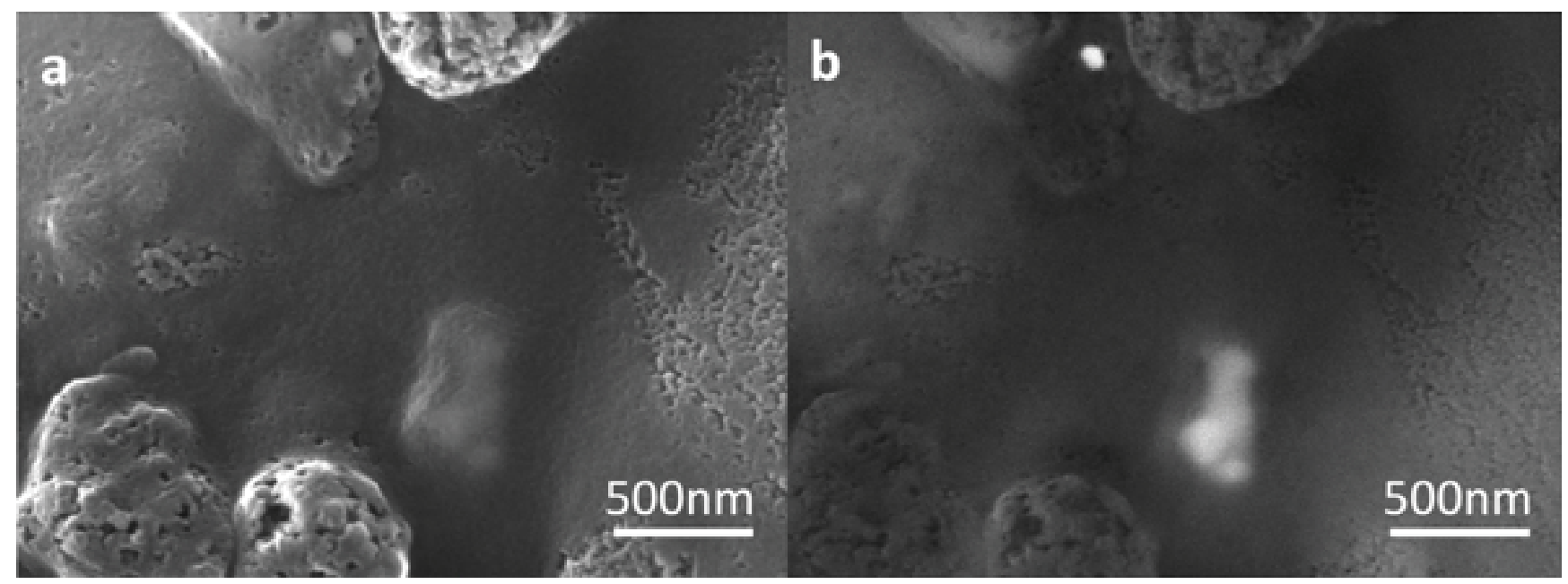

Figure 2: SEM characterization of detected $\mathrm{TiO}_{2}$ particles in a liver sample. (a) The electron microscope image shows a TiO agglomerate below the surface of the liver tissue: (b) The backscattered electron image reveals the spherically shaped primary particles within the agglomerate. 
Citation: Peters RJB, Undas AK, Memelink J, et al. (2018) Development and Validation of a Method for the Detection of Titanium Dioxide Particles in Human Tissue with Single Particle ICP-MS. Current Trends Anal Bioanal Chem 2(1):74-84

In the literature, the analysis of (nano)materials often focusses on detection and characterization, while the sample preparation is ignored. The isolation of nanomaterials is usually carried out by chemical (mineral acids or strong bases) or enzymatic digestion of the matrix. Traditional chemical digestion involves the use of strong mineral acids and high temperatures, as applied in this study for the determination of total-Ti [2,31]. However, this approach cannot be used to determine particulate- $\mathrm{TiO}_{2}$, since these particles may (partly) dissolve, agglomerate or react under these strong acidic conditions. As a consequence, enzymatic and alkaline digestions have been proposed as alternative sample preparation approaches for the analysis of particles in biological tissues [15,32]. Enzymatic digestion involves particle extraction and isolation by digestion of the organic matrix constituents, such as proteins. In this study, however, the tissues were formalin-fixed, i.e. the proteins are cross-linked, and enzymatic digestion alone would probably not work. As a result, it may be more difficult to extract particles from these formalin-fixed tissues. The addition of glycine to the digestion buffer and the use of heat as a pre-treatment for depolymerisation is described by several authors for the isolation of DNA from fixed tissues [33,34]. Glycine reacts with formaldehyde to form $\mathrm{N}$-methyleneglycine or dimethylglycine, thereby depleting the store of formaldehyde in the tissue. The alkalinity of the buffer and heat treatment $\left(100^{\circ} \mathrm{C}\right.$ for $3 \mathrm{hrs}$.) further aids in reversing the cross-linking of proteins. Subsequently, the method involves cooling of the reaction mixture, the addition of proteinase $\mathrm{K}$ and incubation for $16 \mathrm{hrs}$. to digest the denatured proteins [35].

For total-Ti an acidic digestion with $\mathrm{HNO}_{3}$ and $\mathrm{HF}$ was applied, followed by instrumental analysis using ICPHRMS. The trueness of the method was $112 \pm 34 \%$ with a LOD of $0.01 \mathrm{mg} \mathrm{Ti} / \mathrm{kg}$. The repeatability $\left(\mathrm{s}_{\mathrm{r}}\right)$ and within-lab reproducibility $\left(\mathrm{S}_{\mathrm{RL}}\right)$ were $24 \%$ and $31 \%$, respectively. The sample preparation methods in this study resulted in analyte concentration of $50 \mu \mathrm{g} / \mathrm{kg}$, therefore the predicted $\mathrm{s}_{\mathrm{r}}$ and $\mathrm{S}_{\mathrm{RL}}$ at this concentration are $22 \%$ and $44 \%$. Since the ratios of the experimentally determined and predicted $\mathrm{s}_{\mathrm{r}}$ and $\mathrm{S}_{\mathrm{RL}}$ are within a ratio of 0.5 to 2 , within the Horowitz ratio as discussed in Results section, the found repeatability and within-lab reproducibility are acceptable.

In total 30 human tissue samples were analyzed with the developed and validated method. The results show a total-Ti content in the range of $0.02-0.09 \mathrm{mg} \mathrm{Ti} / \mathrm{kg}$ in liver and 0.02 $0.4 \mathrm{mg} \mathrm{Ti} / \mathrm{kg}$ in spleen. The total-Ti concentrations found in this study are lower than the few total-Ti concentrations reported in the literature as shown in Table 3.
Based on the literature and the results for total-Ti concentrations in liver and spleen it is expected that particle- $\mathrm{TiO}_{2}$ concentrations will be low $[36,37]$. Since digestion will lead to a further dilution of the analyte, a sensitive instrumental detection technique is required to determine particulate $\mathrm{TiO}_{2}$. spICP-(HR)MS is a relatively new, but well established technique that allows the detection and characterization of (nano-)particles in samples from biological tissues $[2,12,13,38]$. While spICP-MS is still in the early stages of application, it does offer new opportunities for quantitative analysis of low nanoparticle concentrations in complex biological samples. spICPMS, the method that was recently published as an ISO Technical Specification $[14,15]$, has been already validated for determination of silver and gold nanoparticles in fruit juices [39] and silver nanoparticles in chicken meat [20]. It is important to emphasize that spICP-(HR)MS provides only information about particle mass, -number and -size. No information about particle shape is available from this technique and needs to be generated with additional measurements like electron microscopy (EM) with energy dispersive $\mathrm{X}$-ray spectroscopy (EDX). This is analytically challenging since the particle concentration found with spICP-HRMS are very low, implying that a high number of EM images need to be processed. However, this EM analysis has been performed and the results show that combing spICP-HRMS and EM-EDX is a powerful couple [39].

The trueness of the complete spICP-HRMS method was determined to be $32 \pm 7 \%$, however, as explained in the text in the previous section this is an underestimation of the actual trueness. The repeatability and within-lab reproducibility for the mass- and number-based $\mathrm{TiO}_{2}$ concentration were around $20 \%$ and $40 \%$, respectively. For particle size these were $29 \%$ and $24 \%$. When compared with the HorRat predicted $\mathrm{s}_{\mathrm{r}}$ and $\mathrm{S}_{\mathrm{RL}}$ at this concentration (22\% and $44 \%)$ the found repeatability and within-lab reproducibility are acceptable for particle concentration (particle mass and number) as well as for particle size. The repeatability and within-lab reproducibility for particle size are more or less the same, which is an indication that it is not the measurement but the polydispersity of the analyte itself which is causing this uncertainty. The LOD for mass concentration was 0.005 $\mathrm{mg} \mathrm{Ti} / \mathrm{kg}$ and the LOD and LOQ for size were respectively 50 and $85 \mathrm{~nm}$.

The concentrations of particle $\mathrm{TiO}_{2}$ in 30 analyzed

Table 3: Data from this study and literature for total -Ti concentrations in human liver and spleen.

\begin{tabular}{|l|l|l|l|}
\hline & Liver $\mathbf{( m g / k g})$ & Spleen $\mathbf{( m g / k g )}$ & Comments/Reference \\
\hline Total-Ti & $0.04 \pm 0.02$ & $0.08 \pm 0.1$ & This study, ICP-HRMS, $\mathrm{n}=30$ \\
\hline & 1.3 & 0.2 to 1.4 & NRC, X-ray fluorescence analyses [31] \\
\hline & $1.7 \pm 3.4$ & $1.9 \pm 2.4$ & Yukawa, et al., neutron activation analysis, $\mathrm{n}=15$ (liver) and $\mathrm{n}=6$ (spleen) [32] \\
\hline
\end{tabular}


Citation: Peters RJB, Undas AK, Memelink J, et al. (2018) Development and Validation of a Method for the Detection of Titanium Dioxide Particles in Human Tissue with Single Particle ICP-MS. Current Trends Anal Bioanal Chem 2(1):74-84

human samples ranged from $0.01-0.08 \mathrm{mg} \mathrm{Ti} / \mathrm{kg}$ in liver and from $0.01-0.1 \mathrm{mg} \mathrm{Ti} / \mathrm{kg}$ in spleen. On the average, particle $\mathrm{TiO}_{2}$ explained up to $67 \%$ of the total-Ti concentrations. The detected $\mathrm{TiO}_{2}$ particles had a size range of 85 to $720 \mathrm{~nm}$ with an apex of $130 \mathrm{~nm}$. Based on a LOQ for particle size of $85 \mathrm{~nm}$ we found out that $24 \%$ of the $\mathrm{TiO} 2$ particles in the number-based size distribution were $<100 \mathrm{~nm}$. The methods developed in this study are useful for future human biomonitoring studies and risk assessments of the exposure to $\mathrm{TiO}_{2}$ and other particulate materials.

\section{Funding}

The research was commissioned and financed by The Netherlands Food and Consumer Product Safety Authority (NVWA) and the Ministry of Economic Affairs.

\section{Ethics Approval}

Written informed consent was obtained during life from the people of which the organs were used in this study, that allowed the use of their entire bodies for educational and research purposes. All ethical regulations concerning the use of these organs were followed, and approval for this specific scientific use was obtained from the board of University Medical Centre Utrecht.

\section{References}

1. https://minerals.usgs.gov/minerals/pubs/mcs/2016/ mcs2016.pdf

2. Peters RJB, Van Bemmel G, Herrera-Rivera Z, et al. (2014) Characterization of titanium dioxide nanoparticles in food products: Analytical methods to define nanoparticles. J Agri Food Chem 62: 6285-6293.

3. Weir A, Westerhoff P, Fabricius K, et al. (2012) Titanium Dioxide Nanoparticles in Food and Personal Care Products. Environ Sci Technol 46: 2242-2250.

4. $\mathrm{NCl}$ (1979) Bioassay of titanium dioxide for possible carcinogenety. Natl Cancer Inst Carcinog Tech Rep Ser.

5. Warheit DB, Donner EM (2015) Risk assessment strategies for nanoscale and fine-sized titanium dioxide particles: Recognizing hazard and exposure issues. Food Chem Toxicol 85: 138-147.

6. FAO (2006) Titanium Dioxide. In: Chemical and Technical assessment.

7. Pele LC, Thoree V, Bruggraber SF, et al. (2015) Pharmaceutical/food grade titanium dioxide particles are absorbed into the bloodstream of human volunteers. Part Fibre Toxicol 12: 26-32.

8. Bockmann J, Lahl H, Eckert T, et al. (2000) Blood titanium levels before and after oral administration titanium dioxide. Phamazie 55: 140-143.

9. Powell JJ, Faria N, Thomas-McKay E, et al. (2010) Origin and fate of dietary nanoparticles and microparticles in the gastrointestinal tract. J Autoimmunity 34: 226-233.

10. Geraets L, Oomen AG, Krystek P, et al. (2014) Tissue dis- tribution and elimination after oral and intravenous administration of different titanium dioxide nanoparticles in rats. Part Fibre Toxicol 11: 30-37.

11. Farrell TP, Magnuson B (2017) Absorption, Distribution and Excretion of Four Forms of Titanium Dioxide Pigment in the Rat. J Food Sci 82: 1985-1993.

12. Shi H, Magaye R, Castranova V, et al. (2013) Titanium dioxide nanoparticles: A review of current toxicological data. Part Fibre Toxicol 10: 15-25.

13. Zeman T, Loh EW, Cierny D, et al. (2018) Penetration, distribution and brain toxicity of titanium nanoparticles in rodents' body: A review. IET Nanobiotechnology.

14. Winkler HC, Notter T, Meyer U, et al. (2018) Critical review of the safety assessment of titanium dioxide additives in food.

15. Bachler G, von Goetz N, Hungerbuhler K (2015) Using physiologically based pharmacokinetics (PBPK) modeling for dietary risk assessment of titanium dioxide (TiO2) nanoparticles. Nanotoxicol 9: 373-380.

16. Heringa MB, Geraets L, van Eijkeren JCH, et al. (2016) Risk assessment of titanium dioxide nanoparticles via oral exposure, including toxicokinetics considerations. Nanotoxicol 10: 1515-1525.

17. Laborda F, Bolea E, Jimenez-Lamana J (2014) Single Particle Inductively Coupled Plasma Mass Spectrometry: A Powerful Tool for Nanoanalysis. Anal Chem 86: 2270-2278.

18. Peters RJB, Herrera-Rivera Z, Undas A, et al. (2015) Single particle ICP-MS combined with a data evaluation tool as a routine technique for the analysis of nanoparticles in complex matrices. J Anal At Spectrom 30: 1274-1285.

19. ISO/TS 19590 (2017) Nanotechnologies-Size distribution and concentration of inorganic nanoparticles in aqueous media via single particle inductively coupled plasma mass spectrometry, Geneva, Switzerland.

20. Peters RJB, Herrera-Rivera Z, van Bemmel G, et al. (2014) Development and validation of single particle ICP-MS for sizing and quantitative determination of nano-silver in chicken meat. Anal Bio Chem 406: 3875-3885.

21. (2011) NanoGenotox report "The generic NanoGenotox dispersion protocol, SOP and background documentation".

22. (2011) NEN 7777, "Environment and Food - Performance characteristics of measurement methods", Delft, The Netherlands.

23. Tuoriniemi J, Cornelis G, Hassellov M (2014) Improving the accuracy of single particle ICPMS for measurement of size distributions and number concentrations of nanoparticles by determining analyte partitioning during nebulisation. $\mathrm{J}$ Anal Atom Spectrom 29: 743-752.

24. Tuoriniemi J, Cornelis G, Hassellov M (2012) Size discrimination and detection capabilities of single-particle ICPMS for environmental analysis of silver nanoparticles. Anal Chem 84: 3965-3972.

25. Currie LA (1995) Nomenclature in evaluation of analytical methods including detection and quantification capabilities (IUPAC Recommendations 1995). Pure Appl Chem 67: 1699-1723.

26. Lee S, Bi X, Reed RB, et al. (2014) Nanoparticle size detection limits by single particle ICP-MS for 40 elements. Environ Sci Technol 48: 10291-10300. 
Citation: Peters RJB, Undas AK, Memelink J, et al. (2018) Development and Validation of a Method for the Detection of Titanium Dioxide Particles in Human Tissue with Single Particle ICP-MS. Current Trends Anal Bioanal Chem 2(1):74-84

27. Horwitz W, Albert R (2006) The Horwitz ratio (HorRat): A useful index of method performance with respect to precision. JAOAC Int 89: 1095-1109.

28. Linsinger TPJ, Peters R, Weigel S (2014) International interlaboratory study for sizing and quantification of $\mathrm{Ag}$ nanoparticles in food simulants by single-particle ICP-MS. Anal Bioanal Chem 406: 3835-3843.

29. Weigel S, Peters RJB, Loeschner K, et al. (2017) Results of an interlaboratory method performance study for the size determination and quantification of silver nanoparticles in chicken meat by single-particle inductively coupled plasma mass spectrometry (sp-ICP-MS). Anal Bioanal Chem 409: 4839-4848.

30. European Commission (2011) Commission Recommendation of 18 October 2011 on the definition of nanomaterial. Off J Eur Communities: Legis 275: 38-40.

31. Wagner S, Legros S, Loeschner K, et al. (2015) First steps towards a generic sample preparation scheme for inorganic engineered nanoparticles in a complex matrix for detection, characterization, and quantification by asymmetric flowfield flow fractionation coupled to multi-angle light scattering and ICP-MS. J Anal Atom Spectrom 30: 1286-1296.

32. Gray EP, Coleman JG, Bednar AJ, et al. (2013) Extraction and analysis of silver and gold nanoparticles from biological tissues using single particle inductively coupled plasma mass spectrometry. Environ Sci Technol 47: 14315-14323.

33. Shedlock AM, Haygood MG, Pietsch TW, et al. (1997) Enhanced DNA extraction and PCR amplification of mitochondrial genes from formalin-fixed museum specimens. Bio Techniques 22: 394-400.

34. Gilbert MTP, Haselkorn T, Bunce M, et al. (2007) The isolation of nucleic acids from fixed, paraffin-embedded tissues-which methods are useful when? PLoS One 6: e537.

35. Carpi FM, Pietro F, Vincenzetti S, et al. (2011) Human DNA extraction methods: Patents and applications. Recent Pat DNA Gene Seq 5: 1-7.

36. National Research Council (2005) Mineral Tolerance of Animals: Second Revised Edition. Washington.

37. Yukawa M, Amano K, Suzuki-Yasumoto M, et al. (1980) Distribution of trace elements in the human body determined by neutron activation analysis. Arch Environ Health 35: 36-44.

38. Tassinari R, Cubadda F, Moracci G, et al. (2014) Oral, short-term exposure to titanium dioxide nanoparticles in Sprague-Dawley rat: Focus on reproductive and endocrine systems and spleen. Nanotoxicology 8: 654-662.

39. Heringa MB, Peters RJB, Bleys RLAW, et al. (2018) Detection of titanium particles in human liver and spleen and possible health implications. Part Fibre Toxicol 15. 